\title{
Virtualidade e Materialidade Ponderações sobre os procedimentos de projeto estruturados por novas tecnologias de informação
}

\author{
Renato Luiz Sobral Anelli*
}

\begin{abstract}
Resumo $\mathrm{O}$ artigo propõe refletir sobre o papel do desenho no ensino e aprendizado do projeto de arquitetura hoje, considerando a presença crescente dessas tecnologias digitais (TI) e seu conflito com a materialidade da construção. Inicialmente é apresentada uma reflexão da atividade do autor como professor de projeto em um estúdio de terceiro ano, meio do curso de graduação em arquitetura do IAU USP. A segunda parte do artigo é dedicada à análise de algumas produções de formas complexas, na arquitetura e nas artes, realizadas na metade do século XX, que contribuem para a reflexão proposta.
\end{abstract}

Palavras-chave: ensino de projeto, tecnologia digital, materialidade da construção.

\section{Virtualidad y Materialidad . Consideraciones sobre los procedimientos de diseño estructurados por nuevas tecnologías de la información}

\begin{abstract}
Resumen El artículo propone reflexionar sobre el papel del diseño en la enseñanza y el aprendizaje del proyecto de arquitectura hoy, considerando la creciente presencia de estas tecnologías digitales (TI) y su conflicto con la materialidad de la construcción. Inicialmente se presenta una reflexión de la actividad del autor como profesor de proyecto en un estudio de tercer año, medio del curso de graduación en arquitectura del IAU USP. La segunda parte del artículo está dedicada al análisis de algunas producciones de formas complejas, en la arquitectura y en las artes, realizadas a mediados del siglo $X X$, que contribuyen a la reflexión propuesta.
\end{abstract}

Palabras clave: enseñanza del diseño, tecnología digital, materialidad de la construcción.

\section{Virtuality and Materiality . Ponderations on design procedures structured by new information technologies}

\begin{abstract}
The article proposes to reflect on the role of drawing in the teaching and learning of architectural design today, considering the growing presence of these digital technologies (IT) and its conflict with the materiality of the building. Initially it is presented a reflection of the author's activity as a professor of design in a third studio year, half of the undergraduate program in the IAU USP architecture. The second part of the article is devoted to the analysis of some complex forms design and production, in architecture and in the arts, in the middle of the $X X$ century, that contribute to the proposed reflection.
\end{abstract}

Key words: design education, digital technology, construction materiality. 
urante alguns anos foi realizada uma experiência de introdução de novos procedimentos de projeto de arquitetura utilizando softwares paramétricos e máquinas de fabricação digital no estúdio de projeto de terceiro ano do IAU USP ${ }^{1}$. A incorporação das TI no estúdio de projeto ocorreu de modo experimental, buscando-se levar o aluno a questionar os limites e potencialidades do trânsito entre o virtual/digital e o real/ material. Por esse motivo, os modelos digitais e físicos foram estratégicos na disciplina. Usamos dois tipos de softwares paramétricos. Os do tipo Rhinoceros / Grasshopper, para explorar superfícies complexas, e os do tipo Building Information Model (BIM), para a concepção de projetos a partir de padrões pré-estabelecidos e sistematizados nas famílias de componentes.

A organização dos modelos digitais para a produção de modelos físicos através de cortadoras laser foi estratégico para o equacionamento da disciplina, pois esse tipo de fabricação digital exige a planificação das formas e sua separação em componentes para a montagem manual. Essa transição, relativamente trabalhosa, entre o digital e o material introduz o aluno ao problema da projetação da produção.

O estúdio de projeto é estruturado em vários exercícios a partir de uma rede de infra-estrutura urbana de mobilidade, a qual permite uma abordagem sistêmica por toda a cidade. Ano a ano foi sendo desenvolvido um sistema em rede de corredores de ônibus e VLT na cidade de São Carlos, sendo trabalhado os projetos das vias, das paradas e abrigos, das estações de integração associadas a planos de reurbanização. Equipamentos públicos de educação, saúde e cultura compõe o plano de reurbanização, associando a melhor acessibilidade, graças ao transporte público, à oferta de serviços básicos. O objetivo é essencialmente urbanístico, pois é simulado um novo modo de conceber a cidade a partir da redistribuição de usos e infraestrutura de transporte.

São definidas abordagens diferentes para os projetos dos equipamentos públicos maiores, utilizando sistemas convencionais padronizados pelo FDE - Fundação para o Desenvolvimento da Educação, e para os abrigos e estações de transportes públicos, que teriam formas excepcionais, variáveis de acordo com as condições de implantação na cidade. Para os primeiros é usado BIM, para os demais, Rhinoceros/ Grasshopper. Os projetos das escolas públicas partem da análise da implantação e da adequação da proposta padronizada. Os estudos iniciais são realizados pelas equipes com desenhos manuais de giz na lousa, de modo que possam ser discutidos coletivamente pela classe. A partir de pequenos croquis e desenhos esquemáticos feitos pelas equipes, de improviso na lousa, é feita a discussão e elaboração das suas questões centrais para o projeto. A transição para os softwares exige treinamento adequado e acesso

* Renato Luiz Sobral Anelli é Arquiteto, Professor Sênior do Instituto de Arquitetura e Urbanismo da Universidade de São Paulo, ORCID <https://orcid.org/00000002-2036-5897>. a infraestrutura de hardware específica. Mas a questão central é a interação entre alunos e os software no processo criativo. Os desenhos auxiliares são comuns, croquis de apoio, que permitem a rápida formalização das concepções do projeto. O software conduz à objetivação do projeto e sua preparação para a produção. Desenho no papel e na tela, entendendo-se as especificidades de cada meio. No caso do Revit, o estúdio 
1 Disciplinas Projeto $3 \mathrm{~A}(\mathrm{IAU} 734)$ e Projeto 3 B (IAU 735), professores Marcelo Tramontano e Renato Anelli. de projeto se transforma fisicamente, pois os projetos passam a ser desenvolvidos pelas equipes em sistema cooperado, com a utilização de um modelo digital no servidor central, e os alunos trabalhando em partes dele a partir de seus computadores pessoais.

O software permite e facilita a geração modos tradicionais de representação arquitetônica, tais como cortes e plantas, agora retirados diretamente do modelo virtual em 3D. O aluno se organiza para aprender dominar esses códigos de representação ao "costumerizar" o software, estabelecendo os parâmetros dos produtos que serão gerados. As plantas e cortes tendem a ter um bom nível de detalhamento e correspondem ao desenvolvimento de cada componente da construção inserido no modelo 3D. O aluno desenvolve o controle da relação entre desenho e componentes/sistemas construtivos simultaneamente, pois não se faz o projeto e depois o modelo. Qualquer alteração do projeto ocorre no modelo e em todas as peças gráficas geradas. Graças ao rigor no pensamento construtivo mediado pelo software, o planejamento da produção do modelo físico constitui etapa relativamente simples, se comparada ao outro exercício.

O projeto dos abrigos das paradas de VLT é menos convencional, pois os softwares Rhinoceros e o Grasshopper trabalham com scripts de geração de forma, sistematizados para produzirem algumas soluções de default. Trata-se de novos desafios, pois trabalham com estes algoritmos para a geração de uma forma apresentados em uma linguagem amigável, gerando complexas curvas, superfícies e suas variações com certa facilidade. Aqui a forma não preexiste ao computador, mesmo que sejam desenvolvidos croquis, pois ela é gerada diretamente através de algoritmos abstratos. Trata-se de uma possibilidade de expressão de um projeto quase independente do desenho, o qual seria totalmente gerados por esses mecanismos e suas lógicas matemáticas/digitais. Sua potencialidade para concretizar formas complexas levou à que alguns arquitetos argumentar que se trata de um estilo arquitetônico, como o parametricismo defendido por Patrik Schumacher (2009).

Além dos defaults que facilitam formas pré-determinadas, o programa possui sistematizações próprias para a sua transformação em peças planificadas para serem produzidas pela cortadora laser. O desafio de planejamento da transformação do digital para o material torna-se assim limitado pelos caminhos pré-determinados do próprio programa. Essa limitação oferece o risco de repetição excessiva de certas soluções, além de dificultar a exploração das potencialidades construtivas e estruturais de formas complexas. Apesar das semelhanças formais com as leves e econômicas cascas de Felix Candela ou de Eladio Diestes, as curvaturas geradas pelos defaults desses programas não tem o mesmo objetivo.

Um dos abrigos projetados pelos estudantes pode exemplificar melhor o problema. A forma combina em uma só peça a estrutura e a cobertura aberta para dois lados através de uma torção da superfície, permitindo a alternância de acessos e de proteção. Para a produção do modelo físico utilizando de cortadora laser, a superfície curva é dividida em faces planas, com pequenas abas para serem dobradas e coladas. Estas formam uma nervura que estrutural a superfície curva da casca, mas que para cumprir essa função corretamente, elas devem seguir linhas de força da forma, o que não é previsto pelo default do software. Seria necessário um controle do software, o que exige domínio de linguagens de computação pouco familiares aos arquitetos. O próprio software divide a superfície complexa em faces triangulares planas para o corte a lazer, resultando um modelo físico por construção de componentes em um 
processo de difícil interação. A correspondência entre formas complexas e estruturas econômicas ,presentes nas obras de Candela e Diestes realizadas por manufatura, está ausente da produção parametricista, apesar da capacidade muito superior dos softwares em construir formas complexas.

Recentemente o grupo de pesquisa Nomads construiu de fato um modelo de dimensões maiores a partir da concepção de uma superfície complexa, posteriormente cortada em peças metálicas para serem montadas. O algoritmo estilizado pela interface do software não corresponde a um desenho da forma de estrutura que aproveite as curvas para ser econômica. Nessa escala, a fabricação digital dos componentes não evita que o processo de construção seja árduo, ao contrário daqueles com impressora 3D de polímeros, que sedimenta materiais. Trata-se de algo que deve ser montado manualmente, edificado com esforço e dificuldade. Equipamentos de Proteção Individual, como grossas luvas, são necessários para evitar o corte das arestas ásperas dos componentes.

Aproximadamente na mesma época, no Metalab da Universidade de Houston, foi realizada uma releitura de uma forma do artista austríaco Frederick Kiesler, A Endless House (1958/59). Trata-se de uma construção feita por Andrew Vrana e Joe Meppelink, do Metalab, implantada no jardim da escola de arquitetura. Ela se propõe a ser uma reinterpretação e reconstrução da Endless House. Concebida por Kiesler como uma gruta de meditação do Frederick Kiesler, esse projeto e seus modelos em papier marcher estavam sintonizados com a arte informal e o expressionismo abstrato contemporâneos. Sua construção faz parte de um processo que tem como base de projeto um tipo de desenho expressivo, de gestos rápidos, compatível com esses movimentos artísticos, para ser depois transformado em desenho técnico. O objeto que deu origem à interpretação dos pesquisadores de Houston, foi o Bucephalos, constituído por uma "gruta de meditação" em escala 1:1, produzida pelo próprio Kiesler, enfrentando o material para construir uma trama no espaço capaz de envolver seu corpo. Após concluída, o artista a usou como espaço de meditação, deitando dentro dela. Há uma relação direta da forma com o efeito sensorial sobre o corpo, seja na sua construção, seja na fruição dela concluída.

Esse tipo de fruição da arte não é estranha a nós no Brasil, basta lembrarmos de Lygia Clarke com as sua baba antropofágica e a rede de elásticos já no começo da década de 70. Uma vanguarda artística com muita semelhança com as questões colocadas por Kiesler, em especial essa experiência física dos objetos tocando o corpo e construindo o espaço para uma fruição sensorial, quase sensual da obra de arte.

É impossível ter esse tipo de fruição dentro da gruta feita digitalmente em Houston. Desnecessário afirmar que essas formas metálicas são cortantes, como descobriram os pesquisadores de São Carlos. A referência ao trabalho de Kiesler é apenas uma reprodução da forma em sua aparência superficial, sua complexidade geométrica. Todos os objetivos e a essência da concepção de arquitetura e arte que moviam Kiesler desaparecem, a não ser essa complexidade formal da superfície. É necessário reconhecer que algo se perde nessa releitura e nesse processo de produção digital da forma e da construção. E não é pouca coisa.

Para concluir esta reflexão, apresentamos a seguir dois casos brasileiros de formas complexas modernas. Pela sua similaridade, as formas irregulares e complexas que 
os softwares paramétrico permitem exigem uma análise da forma livre na arquitetura brasileira. O primeiro caso a ser examinado é a relação desenho e estrutura na arquitetura de Oscar Niemeyer. O segundo é uma escada helicoidal concebida por Lina Bo Bardi para o Masp.

Vários autores já relacionaram as formas de Niemeyer a um peculiar modo da arte e arquitetura moderna brasileira em entender a paisagem Os desenhos em croquis foram instrumentos estratégicos para essa arquitetura. Os três croquis reunidos por Sophia Telles em um artigo sobre Lúcio Costa, de Le Corbusier, Oscar Niemeyer e Paulo Mendes da Rocha revelam uma sequência de proposições para a relação arquitetura e paisagem natural. A linha do horizonte, como superfície plana ou agitado perfil das montanhas foi um tema constante nas representações da paisagem brasileira desde Franz Post, sendo retomado e interpretado pela arte e arquitetura moderna em várias ocasiões.

A partir de Pampulha, em especial a igreja de São Francisco de Assis, Niemeyer passa a reproduzir perfis do horizonte montanhoso em suas formas. Desenhos definidos nos croquis, trazem já na concepção plástica um sentido de estrutura. Para isso o domínio das construções em concreto armado foi essencial. O material em estado líquido, vertido nas fôrmas, oculta a ferragem estrutural que permite que as formas livres fiquem em pé. Ao tornar-se um só material maciço, o concreto apaga qualquer esforço de montagem de componentes e ou de separação da forma em elementos de composição. Pier Luigi Nervi criticou essa operação, reclamando que as formas reversas da cúpula invertida do Congresso iam contra a lógica da economia das estruturas que funcionam à compressão, como arcos e abóbadas, pois exigiria armaduras potentíssimas ocultas pelo concreto. Ao defender Niemeyer, seu calculista, o engenheiro Joaquim Cardozo argumentou que a potencialidade do concreto armado poderia levar a formas inimagináveis anteriormente e que esse seria o sentido inovador da arquitetura moderna. A economia da estrutura não era mais o objetivo, mas sim a sua capacidade simbólica. Os desenhos figurativos de traços sintéticos feitos por Niemeyer exigiram um árduo processo manual de interpretação técnica para se tornarem estruturas complexas, mas cuja complexidade é ocultada pelo próprio concreto armado utilizado.

O desenvolvimento de uma outra forma complexa, a escada concebida (e não construída) por Lina Bo Bardi para o Masp permite outra análise. Nos primeiros estudos para o museu, que não tinha ainda a fachada de vidro, mas sim uma fachada opaca com revestimento rústico, a escada seria uma gigantesca helicoidal. Ela atravessaria continuamente todos os andares até chegar ao ultimo evitando a segmentação excessiva desse percurso, como acabou ocorrendo na obra construída.

Nos primeiros croquis ela explora a geometria dessa forma, que evolui pelo espaço, em alguns desenhos de um modo mais orgânico. Ela procura algo que fosse um equilíbrio, uma possível reunificação entre o orgânico e o não orgânico, o natural e o antinatural.

No desenvolvimento da concepção surgem nervuras, que parecem estar na vertical, finíssimas, como se fossem pré-fabricadas e montadas. Para isso o desenho se torna geométrico retirado da projeção a partir de uma planta circular. Pelos desenhos se percebe o esforço em tentar controlar todos os aspectos e detalhes. Ficam registrados as técnicas para controlar as verdadeiras dimensões dessas peças em uma superfície que se desdobra como uma hélice. 
Ainda que essa escada não tenha sido construída, cabe uma comparação com a do Solar do Unhão em Salvador, que ela fez na mesma época. Nela o objetivo foi conceber a geometria dessa mesma forma, uma hélice, dentro de uma planta quadrada, feita em madeira. Cada peça de madeira, cada piso de degrau tem uma forma própria e foi toda construída com técnicas muito simples, que eram usadas para fazer os carrosde-boi no sertão rural do Nordeste.

A relação entre esses casos e as experiências com os softwares paramétricos tem por objetivo refletir sobre o modo como passamos por essa mudança de paradigma na arquitetura e no design.

A intimidade das gerações mais novas com o espaço virtual é tal, que acabam por tê-lo como uma nova natureza. Trata-se de uma nova condição, uma nova experiência de mundo, que naturaliza o mundo digital/virtual em detrimento da experiência material e sensorial que marcou os arquitetos e artistas modernos com Oscar Niemeyer, Lina Bo Bardi, Frederick Kiesler e Lygia Clark. Pode haver uma semelhança formal, por exemplo, entre a obra de Kiesler e os experimentos em Houston e São Carlos, no entanto, as formas são despojadas dos seus significados. Ocorre, por outro lado, um certo afastamento em relação com o passado recente, como se vivêssemos uma ruptura absoluta devido às novas tecnologias de projeto, como se pode depreender dos postulados de Schumacher.

A noção de ruptura contemporânea agrava sobremaneira as dependências em relação às novas tecnologias de informação, softwares e processos de projetação. Não se percebe aquilo que esses processos trazem de indução introjetada nos seus algoritimos e defaults. Naturaliza-se determinados padrões de formas, procedimentos de formalização que tem suas referências próprias, mas que são todas ocultas internamente a esses softwares.

Na situação brasileira, agrega-se uma questão de ordem econômica, além da cultural, que é a da construção de uma dependência tecnológica em relação aos softwares. É fantástico ver Lina Bo Bardi fazer com madeira e técnicas de construção de carro-de-boi uma escada com geometria altamente complexa, uma helicoidal em um quadrado, sem usar software. O Brasil já tive o Cinema Novo, que era uma câmera na mão e uma ideia na cabeça, a Tropicália e as versões da arte povera. A ignorância desses momentos de construção cultural no passado pré-digital coloca para o presente digital a precoce obsolescência de conhecimentos culturais acumulados, que seriam imprescindíveis para um melhor posicionamento no turbilhão dos desafios contemporâneos.

\section{Referências bibliográficas}

CARDOZO, J. Forma estática - forma estética. Módulo, Rio de Janeiro, n. 10, p. 3 - 6, ago. 1958.

NERVI, P. L. Critica delle strutture. Casabella Continuità, Milão, 223, jan. 1959, p. 55.

SCHUMACHER, P. Parametricism: A New Global Style for Architecture and Urban Design. Architectural Design, jun. 2009, p. 79.

TELLES, S. S. Forma e Imagem. AU, São Paulo, 55, p. 91-95, 1994 e TELLES, S. S. Oscar Niemeyer: técnica e forma. Óculum, Campinas, 2, 1992.

Recebido [Ago. 27, 2020] Aprovado [Fev. 28, 2021]
TELLES, S. S. Lúcio Costa: monumentalidade e intimismo. Novos Estudos CEBRAP, São PauIo,25, 1989. 